\title{
Contracampo
}

Natureza, paisagem e

representação na fotografia

de Claudia Jaguaribe

\section{Nature, landscape and \\ representation in the \\ photography of Claudia \\ Jaguaribe}

abr/2017-jul/2017

revista eletrônica do Programa de Pós-Graduação em Comunicação

da Universidade Federal

Fluminense e tem como objetivo contribuir para a reflexão crítica em torno do campo midiático, atuando como espaço de circulação da pesquisa e do pensamento acadêmico.

\section{FERNANDO NASCIMENTO GONÇALVES}

Doutor em Comunicação pela ECO-UFRJ (2003) com pós-doutorado em sociologia pela Universidade René Descartes, Paris V- Sorbonne (2008). Atualmente é professor da Faculdade de Comunicação Social da Universidade do Estado do Rio de Janeiro, habilitação Relações Públicas. Atua nas áreas de comunicação, arte, fotografia, tecnologia, sociabilidade e produção subjetiva. Brasil.

fng@ueri.br

\section{PPGICOM comsiciatio UFF}

AO CITAR ESTE ARTIGO, UTILIZE A SEGUINTE REFERÊNCIA:

GONÇALVES, Fernanda Nascimento. Natureza, paisagem e representação na fotografia de Claudia Jaguaribe. Contracampo, Niterói, v. 36, n. 01, pp. 06-25, abr. 2017/ jul. 2017.

Enviado em: 06 de novembro de 2016 / Aceito em: 24 de janeiro de 2017. 


\section{Resumo}

Este artigo discute a construção das imagens de natureza nas fotografias de paisagem de Claudia Jaguaribe na série Quando eu vi. O texto busca evidenciar como em seus trabalhos a imagem fotográfica constitui ao mesmo tempo material expressivo e uma reflexão sobre as lógicas que organizam nossos modos de ver e de mostrar o mundo. Para tanto, serão analisados cinco trabalhos da série e os procedimentos realizados pela artista para problematizar as noções de "natureza" e de "paisagem" na fotografia. Os questionamentos da artista inscrevem-se nas discussões realizadas na arte contemporânea sobre o arquivo, onde fotografia não é tratada apenas como informação visual, mas como dispositivo que permite discutir sistemas e códigos de representação e a paisagem, como um dispositivo que modula nossas percepções e relações com os espaços naturais e construídos.

\section{Palavras-chave}

Fotografia; Paisagem; Arte; Documento; Representação.

\section{Abstract}

This article aims to discuss the construction of images in Claudia Jaguaribe's nature landscape photographs in the series "Quando eu vi". The text seeks to demonstrate how in Jaguaribe's work photographs constitute at once expressive materials and a reflection on the logics which organizes our forms of seeing and of showing the world. Therefore, the text will examine five works from the mentioned series and review the procedures performed by the artist to critically discuss the notions of "nature" and "landscape" in photography. The questions raised by the artist are part of the discussion on the archive in contemporary art where photography is considered as device which allows to discuss systems and codes of representation and the landscape is seen as a device which modulates our perceptions and relations with natural and constructed spaces.

Keywords

Photography; Landscape; Art; Document; Representation. 


\section{Introdução}

O presente artigo discute os processos de construção da imagem e a noção de paisagem natural nos trabalhos que compõem a série fotográfica Quando eu vi (2007), da artista carioca Claudia Jaguaribe. O texto argumenta que em seus trabalhos a imagem fotográfica constitui ao mesmo tempo material expressivo e uma reflexão sobre as lógicas que organizam nossos modos de ver e de mostrar o mundo.

A discussão proposta pelo texto se inscreve nas reflexões sobre o papel que a fotografia contemporânea ${ }^{1}$ parece ter hoje na redefinição dos parâmetros de apreensão e mediação da experiência social através da imagem. Para diversos autores dos campos da Filosofia, da História da Arte e da Fotografia, as imagens no campo da arte constituem um fenômeno não negligenciável por discutirem a questão da representação e dos regimes de enunciação do visível na fotografia.

Ao inventariar e discutir nossos sistemas de representação, muitos trabalhos de fotografia na arte contemporânea parecem propor, na verdade, uma releitura crítica e conceitual de nossos modos de ver, de viver em sociedade e de nos relacionarmos com a história (FRIED, 2012). Com isso, embora não de forma exclusiva, a fotografia na arte torna-se uma questão relevante para as teorias da fotografia pois desloca a questão do sentido da imagem da pura fruição para um campo de tensão dado pelas relações entre quem produz, o que imagem mostra e quem a vê.

A partir do exame dessas questões, o texto se propõe a analisar cinco das doze obras que compõem a série Quando eu vi: Bibliotecas, A Mata, Serie Branca III, Igarapé e Neblina. A análise se concentrará na construção da visualidade que caracterizam esses trabalhos através da identificação e da descrição das operações que os tornam possíveis: espelhamento, fragmentação e introdução da figura humana na paisagem natural.

O texto busca mostrar como os procedimentos acionados pela artista fazem a imagem performatizar os problemas que elas próprias enunciam, ao produzir efeitos necessários para discutir imagem e paisagem como construções técnica, histórica e cultural. É por meio dessas ações, finalmente, que a artista evidencia a imagem como problema de representação, no sentido de um questionamento sobre os modos de ordenamento da percepção e da significação, conforme o entende Rancière (2009).

\footnotetext{
1 Embora o termo "fotografia contemporânea" abarque a experiência do fotográfico em campos diversos, e não apenas na arte, será usado aqui especificamente para tratar da fotografia no contexto da arte contemporânea.
} 


\section{A fotografia na arte como questão de comunicação}

Apesar de ser considerada - pelo menos desde Benjamin, Barthes, Flusser e Sontag - como objeto técnico, teórico e político, foi apenas nos anos 70 que a fotografia passou a ser legitimada como "objeto artístico" (ROUI LLÉ, 2009). Mais do que uma questão da arte, porém, este status parece apontar para uma mudança mais profunda no modo de se considerar as imagens fotográficas. Estas deixam de ser vistas apenas como narrativas e representações fiéis do mundo e a ser legitimadas como artefatos, objetos reais e ao mesmo tempo ficcionais. Não por acaso, as mais importantes teorizações sobre a fotografia surgem neste mesmo período, em que na arte a fotografia começa a ser considerada como elemento expressivo e obra, com a condição de que deixe de ser considerada apenas como espelho e narrativa mimética do real.

Embora a área de Comunicação se ocupe historicamente do estudo da fotografia, principalmente dos pontos de vista de sua significação, de suas funções sociais e da construção da memória, atualmente é do campo da história da arte que tem surgido as principais contribuições para um entendimento renovado da imagem fotográfica como prática social, cultural e histórica. Aprofundando perspectivas abertas por Warburg, Benjamin e Flusser e seus olhares para a imagem como experiência estética capaz de modular nossas percepções de mundo, pensadores como Rancière, Didi-Huberman e Michel Poivert vêm discutido os modos de produção, circulação e apreciação das imagens e os valores e as funções atribuídos à imagem documental em diferentes contextos.

No campo da História da Arte, por exemplo, Didi-Huberman vem renovando o interesse na imagem através de suas arqueologias visuais, tanto a partir da arte quanto a partir da história, demonstrando a importância de não se esgotar a investigação sobre a imagem enquanto conteúdo visual nem de não se preocupar apenas com seu significado enquanto representação e sim como questão de enunciação e de ordenação do visível, ou seja, como operação de montagem que produz conhecimento a partir de jogos com o real (DIDI-HUBERMAN, 2006).

Para historiadores da fotografia como Michel Poivert, a experiência do fotográfico na atualidade, dentro e fora da arte, indicaria o surgimento gradual de uma nova sensibilidade relativa, por exemplo, ao tratamento dos temas (guerra, dor, miséria) no fotojornalismo, por meio de um olhar construído e trabalhado não raramente a partir dos códigos visuais da história da arte $^{2}$ e também à emergência

\footnotetext{
2 Poivert faz referência às referências às madonas e pietás que povoam fotoreportagens de guerra nos anos 90, como a célebre "pieta" de Kosovo (1990), de George Mérillion, e a madona algeriana de Hocine, de 1997 (Poivert, 2010, p. 77).
} 
do fotógrafo como "autor" de imagens e editor de realidades por meio do registro documental. É quando a fotografia "de informação" passa a ser concebida também, sobretudo a partir dos anos 80, como fato "cultural" (POIVERT, 2010). Não que a imagem tenha perdido seu caráter informativo, mas compreende-se que com a imagem o que se faz não é mostrar um fato em si, mas construí-lo por meio de uma narrativa codificada e legitimada que tende a nos fazer olhar para a imagem como conteúdo visual e não como artefato sociotécnico.

Investigando a chamada fotografia contemporânea, Poivert afirma que uma de suas características seria não mais propor uma revelação do mundo, mas "a evidência do caráter artificial de sua construção" (POIVERT, 2010, p. 225). Apesar de ser historiador da arte e da fotografia, Poivert não faz essa afirmação considerando apenas o campo da arte. O que Ihe interessa é tratar da condição contemporânea da fotografia na arte e também no fotojornalismo para tentar compreender o que esta condição nos fala relativamente às mudanças nos modos de visão e da atenção em nossas sociedades, como também aponta J onathan Crary (2013). Ao falar da fotografia principalmente a partir da arte, Poivert o faz por considerar que há quase três décadas a fotografia vem fundando as bases de sua atualidade numa relação de contemporaneidade com a própria arte. Ou seja, que a fotografia teria nas problemáticas da arte um lugar privilegiado, embora não exclusivo, para repensar seu estatuto, suas funções e seu reconhecimento também em campos como o fotojornalismo.

A perspectiva de Poivert encontra-se aqui com a do filósofo da imagem Patrick Maynard (1997), quando este afirma que ao olharmos uma imagem é possível não apenas atentar para seu aspecto indicial e de representação, mas para o modo como "a imagem apresenta seu motivo e como esse motivo foi usado para fazer a imagem" (MAYNARD, 1997, p. 289). Nesse jogo consistiria o que considero propriamente o aspecto comunicativo da discursividade fotográfica, pois observando os arranjos feitos na imagem e com a imagem seria possível perceber as lógicas de enunciação nas quais a imagem se inscreve e o conjunto de relações que a torna reconhecível em algum grau e em um certo contexto por alguém. Portanto, perscrutar os traços da fatura de uma imagem tornaria possível compreender os modos de ver e de dar a ver que a mobilizam e as maneiras como a imagem modula nossa atenção e percepção.

Certamente, afirmar que a imagem produz efeitos sobre nossa percepção não é uma novidade. Mas o que as imagens fotográficas na arte propõe é considerar esta experiência de afetação a partir de um jogo intencionado com as formas narrativas e com os códigos de representação. Com tais jogos, como os que realiza Jaguaribe, problematiza-se o olhar sobre pessoas, lugares e coisas a partir 
de modos muito particulares de registrar sua presença e rastros no mundo. Tais experimentações com o fotográfico parecem próximas daquilo que Flusser (2008) e Sepper (2013) conceberam como "imaginação", ou seja, processos de produção de imagens que reconfiguram o olhar sobre a experiência a partir de uma reelaboração das representações. É tal operação que muitas das imagens produzidas na arte (embora não apenas elas) parecem realizar.

O que imagens como as que compõem a série Quando eu vi permitem observar e discutir são exatamente algumas das mudanças que vêm ocorrendo na fotografia, particularmente no campo da arte, como observou Poivert. Neste contexto, o registro documental é o ponto de partida para a construção da imagem e não seu fim. É isso o que Ihes um confere o estatuto daquilo que Didi-Huberman chamou de "sintoma" - aquilo que na imagem "suspende o curso normal da representação" (DIDI-HUBERMAN, 2011, p.64). Assumida como uma formapensamento, a fotografia na arte desempenha uma função alegórica que organiza distintos elementos culturais e históricos de modo a elaborar narrativas complexas e quase sempre simbólicas, embora frequentemente ancoradas no registo documental (POIVERT, 2010).

É nesse sentido que nos interessa evidenciar neste texto os aspectos de construção das paisagens naturais "imaginadas" de Cláudia Jaguaribe. Mas é importante dizer que seu interesse pelo tema da paisagem é muito recorrente entre diversos artistas que trabalham com fotografia, de Alice Miceli, Pedro David, Rodrigo Braga a Thomas Struth, Andreas Gursky, Candida Hoffer e Sophie Ristelhueber. É que para eles os espaços urbanos e naturais, a arquitetura e seus interiores são mais do que simples lugares, são espaços de relação, onde se pode observar nossas formas praticar e significar histórica e socialmente espaços naturais e construídos e como essas práticas organizam nossos modos de vida em sociedade.

\section{Paisagens naturais, paisagens construídas}

Nos estudos da área de Comunicação trata-se muito pouco das relações entre fotografia e arte, particularmente com a pintura, de onde a fotografia herdou algumas de suas problemáticas, como apontaram Flores (2012) e Galassi (1981). É sobretudo com os estudos da História da Arte que se percebe uma vinculação (não exclusiva) da fotografia com a história da pintura (GALASSI, 1981) e da fotografia de paisagem com a história da paisagem na pintura (CAUQUELIN, 2009).

É sobretudo do ponto de vista de um certo regime de enunciação, ou seja, das lógicas que constroem condições de dar a ver o sensível e nossos modos de 
apreensão deste, que pintura e fotografia se aproximam. Quando apoiadas na mímese e quando a verossimilhança se torna uma regra e ao mesmo tempo uma condição para a enunciação do visível (RANCIERE, 2009), pintura e fotografia desempenham a mesma função de fazer com que mundo e narrativa supostamente coincidam na bidimensão da imagem.

Isso fica claro na questão da paisagem. Segundo Anne Cauquelin (2009), o termo "paisagem" designa uma construção à qual atribuímos significação. A paisagem é considerada pela autora como uma espécie de moldura que enquadra nossas formas de ver. Ao mesmo tempo em que essa moldura funciona como metáfora da verossimilhança, serve também para modular nosso entendimento e representação idealizada da natureza, que dicotomicamente e por oposição, vai rivalizar com a artificialidade da ação humana. É curioso, porém, que mesmo implicando também artificialidade e intencionalidade, historicamente os mecanismos e as operações de modulação da visão e da percepção quase sempre foram consideradas objetivas e neutras, meras questões de técnica, ao passo que as ações de ordem "subjetiva" geralmente eram desqualificados ou relegados a segundo plano como ficção ${ }^{3}$.

Desse ponto de vista, como constructo, a paisagem, seja na pintura ou na fotografia, lança, para os estudos da Comunicação e da imagem, importantes questionamentos: como apreender uma fotografia cujo interesse não coincide inteiramente com aquilo que mostra? o que somos capazes ou não de reconhecer em uma fotografia, e por quê? O que finalmente vemos quando olhamos imagens? Algumas dessas perguntas são feitas por artistas e discutidas através de suas obras. Claudia Jaguaribe é um desses artistas.

Com formação em História da Arte, Artes Plásticas e Fotografia, a artista carioca radicada em São Paulo realiza desde 1988 uma investigação em torno da natureza da imagem, seja através do retrato ou da paisagem, do vídeo ou da fotografia. Em 2010, recebeu o Prêmio Marc Ferrez da Funarte e atualmente colabora com jornais e revistas nacionais. Em 2014, passou a integrar o "The World Atlas of Street Photography", ao lado de Wim Wenders, Thomas Ruff, Joel Meyerowitz, Phillip-Lorca Di Corcia, J eff Wall, Alex Webb e Cassio Vasconcelos.

Alguns de seus trabalhos recentes mais conhecidos foram sobre paisagens urbanas (Entre Morros, 2010 e Sobre São Paulo, 2011), onde realiza uma crítica da perspectiva como técnica clássica de representação do espaço e o uso da colagem digital para criar paisagens impossíveis apesar de parecerem reais. Esse jogo entre real e ficcional, que alude o real e o ultrapassa, faz parte de seu interesse na

\footnotetext{
${ }^{3}$ Como veremos, este é exatamente o tipo de problematização feito por Jaguaribe em Quando eu vi.
} 
fotografia como prática que a ajuda a pensar formas de refletir sobre as mutações na paisagem e conceber esta última como "uma reinvenção da natureza". Ao mesmo tempo, sua investigação sobre a paisagem é também uma reflexão sobre a própria fotografia e seus códigos visuais de representação.

Mas esses modos de uso da imagem mental para inventariar e inventar paisagens surgiu muito antes, em trabalhos sobre retrato, cotidiano urbano e paisagens naturais como experiências culturais, sendo este último particularmente como espaço de tensão entre o homem e o ambiente dito natural. Um de seus trabalhos mais importantes nesse sentido, embora menos conhecido, é Quando eu vi, de 2007, razão pela qual foi escolhido para ser analisado neste texto.

Do mesmo modo que em suas paisagens urbanas, Jaguaribe discute uma dupla questão em Quando eu vi: a ideia de natureza e de paisagem (e a problemática da tensão entre natural e construído como questão política e cultural) e a fotografia como prática que produz documentos visuais que atestam um real ao mesmo tempo em que o constrói (ROUILLÉ, 2009), e não como algo que simplesmente é elemento de verdade ou repositório da memória.

O que nos interessa aqui, contudo, é menos a análise das imagens enquanto elemento desta discussão e mais os procedimentos de sua construção como estratégia que evidencia os modos como a artista habilita a imagem a produzir tais discussões, ou seja, como ela faz a imagem enunciar de outra forma um real, problematizando a um só tempo paisagem e representação na fotografia.

\section{Quando eu vi}

Quando eu vi é uma série composta por doze imagens fotográficas e um vídeo, produzidos a partir de registros da mata brasileira nas regiões do Rio de Janeiro, São Paulo, Minas Gerais, Amazônia e Pantanal. É também o nome de uma exposição ocorrida em 2007, em Brasília, com curadoria de Marco Delogu. No texto da exposição, o curador afirma que o Brasil pode ser considerado um dos últimos países onde é possível verificar "lugares de natureza intocável no limiar de sua transformação" (DELOGU, 2008). Contudo, é essa concepção de uma natureza "intocada" - oposta ao construído e que corroboraria um ideal idílico, de real e de belo tão presente na pintura acadêmica ${ }^{4}$ e na fotografia documental - que é problematizada nesses trabalhos.

\footnotetext{
4 A pintura acadêmica ou academicista surgiu no século XVII e entrou em crise no final do século XIX. Caracterizava-se por tentar manter o rigor com as regras técnicas, estéticas e formais ensinadas nas academias de arte, onde surgiu e legitimou-se como "belas artes". Em "A partilha do sensível" (2009), Rancière relaciona este modo de fazer imagem ao que chamou de regime poético ou representativo das artes, conjunto de regras e formas expressivas apoiadas na mímese.
} 
A artista utiliza a fotomontagem e a manipulação digital para produzir efeitos visuais nas imagens de modo a evidenciar simbolicamente esse aspecto de invenção da natureza na paisagem e da própria imagem como artifício. Quando se referiu a essa série em 2010, em entrevista à revista Isto É, Jaguaribe afirmou que seu trabalho atravessa a "fronteira entre o documental, o simbólico e talvez o fantástico. São fotos documentais tratadas de forma que pareça uma visão de algo quase impossível" (in ALZUGARAY, 2010). O próprio nome "Quando eu vi” já implica a condição particular que rege a construção dessas imagens. Ao registrar uma natureza supostamente intocada, ao interferir na imagem e ao mostrá-la de modo particular, a artista demonstra o interesse não em documentar a paisagem para representá-la como uma realidade ou uma verdade, mas em discutir a própria ideia do que seja natural e também em questionar os códigos visuais de sua representação.

Como já mencionado, Quando eu vi contém doze série de imagens, mas nos ateremos aqui a apenas cinco delas: Bibliotecas, A Mata, Serie Branca III, I garapé e Neblina, por serem as que considero mais emblemáticas dos usos da imagem como estratégia meta-discursiva para discutir paisagem natural e sua representação como questão na fotografia.

Inspirado no método iconológico de Warburg $^{5}$ (2015), que busca não a significação das figuras, mas as relações que estas mantém entre si, procurei analisar as imagens não a partir das categorias do anacronismo, do intervalo e da sobrevivência das formas visuais e culturais (Pathosformel), mas extrair delas elementos que permitem evidenciar como as imagens de Jaguaribe apontam e realizam ao mesmo tempo um diálogo com as histórias da arte e da fotografia através dos procedimentos utilizados pela artista para construí-las e exibi-las.

Por esta razão, ao observar as séries, minha intenção foi perceber os traços de sua fatura e de suas formas de exposição. Com isso, cheguei à identificação de três gêneros de operações ou de intervenções nas imagens que nos permitem entender os modos como a artista discute a ideia de paisagem natural como construção e que denominei de fragmentação, espelhamento e contraste. Analisando essas imagens na relação com as de outros trabalhos, como Entre Morros e Sobre São Paulo, foi possível perceber que essas operações são recorrentes e podem ser consideradas como constitutivas da linguagem visual de sua fotografia.

\footnotetext{
5 Para a análise dos trabalhos adotamos procedimentos que buscaram não privilegiar a interpretação das imagens, mas os aspectos formais e materiais de suas discursividades visuais, que permitiriam vinculá-los tanto a determinadas lógicas enunciativas quanto às problemáticas da representação e da história da arte e da fotografia. A análise das imagens implica, portanto, a combinação destes procedimentos, inspirados teórica e metodologicamente na iconologia de Warburg e na noção de "conhecimento por montagem" em Benjamin (2011), sistematizado por Didi-Huberman.
} 
No primeiro e segundo trabalhos, de natureza instalativa, nos deteremos na operação de fragmentação, que se refere às paisagens construídas e que só podem ser vistas em sua totalidade com a junção de partes fragmentadas. No terceiro e quarto trabalhos, imagens fotográficas expostas no formato tableau ${ }^{6}$, observaremos a operação de espelhamento, que tem como referência as paisagens que são refletidas na superfície da água. A terceira e última operação aparece em Neblina, que representa a introdução da figura humana na paisagem, com a qual a artista produz um contraste e insere a questão da relação homem x natureza.

A descrição detalhada dos trabalhos e sua feitura não terá como propósito enfatizar seus aspectos técnicos ou formais nem realizar uma análise hermenêutica das imagens, mas evidenciar como sua materialidade nos informa sobre decisões e efeitos expressivos necessários para a realização de seus questionamentos e reflexões.

\section{Bibliotecas e A Mata: a unificação pelo fragmento}

No formato de instalação, "Bibliotecas" apresenta imagens impressas em placas de acrílico simulando livros em quatro estantes. O trabalho é composto por quatro conjuntos de imagens $(50 \times 30 \mathrm{~cm}$ cada) que resultam da aplicação das impressões nas placas e seu posterior enfileiramento. Devidamente combinado e alinhado, cada conjunto de livros-imagem (placas com imagens aplicadas) forma uma única imagem, sugerida visualmente pelo arranjo contíguo das placas enfileiradas nas prateleiras.

\footnotetext{
${ }^{6}$ O formato tableau é o formato expositivo comum da fotografia em galerias e museus, sendo em grandes ou médias dimensões e com moldura, também por motivos mercadológicos. Este formato tem estreita ligação com os formatos da pintura e tem constituído um padrão para a fotografia na arte, embora diversos artistas trabalhem também com projeção, telas digitais ou instalções como forma, inclusive de fugir deste padrão. Estas observações vêm sendo realizadas a partir de trabalho de campo da pesquisa sobre fotografia contemporânea desde 2011 em exposições e também de minha própria inserção como fotógrafo no campo da arte.
} 



Bibliotecas, 2007-2008

FONTE: http://www.claudiajaguaribe.com.br

Apesar dos gestos produzidos pela artista como indicativos de tratamento digital, como é o caso da saturação dos tons verdes das folhas das árvores, não são estas intervenções que chamam a atenção no trabalho. Discutindo a questão da verossimilhança e dos códigos visuais que permitem o reconhecimento de um motivo e seu sentido em uma imagem, em "Bibliotecas", o jogo com a fragmentação e com a montagem fotográfica possibilita a construção de uma paisagem verossímil e ao mesmo tempo evidencia como essa verossimilhança só se efetiva por esta mesma operação artificial de montagem. Ou seja, a artista refaz a paisagem como um gesto simbólico de pensar a paisagem como representação.

Outro gesto que pode ser observado no trabalho é o de quebra de continuidade dada pelos vãos propositais deixados entre alguns livros, notadamente no segundo conjunto, de cima para baixo, à esquerda. Curiosamente, o trabalho mostra que ver e mostrar são mecanismos interdependentes e demandam modos de reconhecimento da visão. Se observarmos a imagem no conjunto onde aparece o maior vão entre os livros-imagem, por exemplo, vemos que, se por um lado, os vãos ficam claros na visualização do conjunto, por outro, não impedem que a imagem se construa no olho, pois resulta de um reconhecimento visual e mental de convenções referentes à imagem de uma "paisagem". O gesto intencional de fazer saber que se trata de uma paisagem é dado pela ordenação linear dos livros na estante e sua contiguidade visual, ou seja, por uma operação de construção que, de certa forma, se naturaliza pelo reconhecimento dos códigos visuais e culturais da imagem.

Outro trabalho que segue o raciocínio da operação de fragmentação e montagem, mas dessa vez para confundir o olhar, é "A Mata". Com 200 x 180 cm, "A Mata" é um backlight, caixa com iluminação com 15 imagens separadas por 
"grades" constituídas pelas molduras de cada foto e que, no conjunto, formam um grande painel ou uma espécie de mosaico, uma paisagem múltipla e mesclada de grande escala para favorecer a visualização dos jogos visuais que se estabelece entre as partes.



A Mata, 2007-2008.

FONTE: http://www.claudiajaguaribe.com.br

Cada fragmento que forma o conjunto é constituído por uma imagem diferente que não necessariamente se completa com a que está ao lado, acima ou abaixo, o que concorre também para confundir nosso olhar. Nesse conjunto fragmentado, há lugares onde algumas imagens se comunicam de forma linear, formando entre si, contiguamente e por extensão, uma pequena paisagem "completa", como vemos nas quatro imagens no canto inferior esquerdo. Em outros, essa relação de continuidade que resulta em verossimilhança é suspensa. Assim como em "Bibliotecas", a paisagem é fatiada. Mas aqui, a operação que junta fragmentos apenas cria paisagens "completas" por partes e não pelo todo, ou seja, não formam uma única paisagem. "A Mata" como paisagem final é resultado da articulação parcial de fragmentos, ora visualmente "compatíveis" entre si, ora incompatíveis, se buscarmos uma coerência linear e verossimilhante do conjunto. $A$ constituição da paisagem, nesse caso, se dá por meio da relação entre as partes fragmentadas e não por uma uniformidade visual total.

Em A Mata, dividir, distribuir e agrupar torna impossível a verossimilhança e o reconhecimento do todo. Esses procedimentos têm como efeito a perda do referencial mimético na contemplação dessa "paisagem descontínua" que resulta 
das articulações entre imagens. É por meio desse jogo entre fragmentação e completude que a artista nos interpela sobre os processos e códigos que nos permitem reconhecer e atribuir determinados significados às imagens e que, ao mesmo tempo, dá a ver o caráter conceitual de toda paisagem. Com tais procedimentos, a artista evidencia os aspectos propriamente comunicativos da discursividade de suas imagens, os jogos que faz com os signos e com as formas narrativas visuais e com os quais desmonta a ideia de pureza e imutabilidade da paisagem natural ${ }^{7}$ e de sua representação clássica na pintura e na própria fotografia.

\section{Séries Branca e Igarapé: espelhamento, mímese e verossimilhaça}

Além da estratégia da fragmentação, em Quando eu vi há trabalhos cuja característica é o espelhamento, outro elemento relacionado à representação mimética na imagem. É o caso das imagens que compõem as séries "Branca" e "I garapé". Em "Branca III", medindo 110 x 73 cm, vê-se uma imagem "cortada ao meio" por um trecho de mata, que divide céu e rio e se tornam quase intercambiáveis.

Produto de uma decisão da artista de duplicar e espelhar céu e rio, tornando ambas camadas simétricas, o trabalho permite discutir exatamente produção de uma realidade "objetiva" através da imagem. No entanto, aqui o procedimento é usado para embaralhar a percepção imediata do que é "real" e do que é espelhamento.

\footnotetext{
${ }^{7}$ No estudos da geografia econômica e política, autores clássicos como Richard Hartshorne (1958) já afirmavam que a pureza atribuída aos ambientes naturais seria uma crença cultivada pelo homem moderno ocidental, que a considera como estática e imutável. Para Hartshorne não há evidências de que a natureza tal qual as conhecemos hoje seja exatamente como há centenas ou milhares de anos. Com base nisso, poderiamos dizer que o que chamamos de natureza seria uma realidade narrada a partir de um olhar particular que a signficou historicamente como tal a partir de dispositivos de representação como a pintura e a fotografia.
} 
Série Branca III, 2007-2008

FONTE: http://www.claudiajaguaribe.com.br

O que resulta dessa operação é uma imagem construída que usa elementos concretos (mata, céu e água) para criar uma outra realidade para imagem, que contém a tensão entre real e sua representação. A imagem que resulta desse jogo com o espelhamento - pela forma de registro e pela manipulação digital que trata as sombras, os contrastes e tons de branco e cinza na imagem - reitera simbolicamente a problemática da mímese e da representação como duplo do real inscrita naquilo que Rancière (2009) chamou de regime enunciativo poético ou representativo.

Em "Igarapé" (110x78 cm) é realizado o mesmo procedimento de espelhamento, mas esta operação terá aqui o efeito de embaralhar a percepção do que é reflexo e o que é refletido, pois a artista recorre à manipulação digital e à fotomontagem para recobrir áreas refletidas da mata na água com outras porções de mata que lhe são contíguas mas que, por sua vez, não se refletem, criando uma paisagem apenas possível na própria imagem final. É como se neste trabalho a artista lançasse mão do mesmo recurso que usou em "A Mata", quando criou um "mosaico" de imagens com fragmentos que, apesar de juntos, não formam entre si uma imagem única, mas sim um conjunto visual descontinuado. A diferença é que em "I garapé" a colagem visual se dá sem as bordas das molduras das imagens de "A Mata", dando a falsa impressão de se tratar de uma imagem única que resulta de registro documental mimético. O trabalho também se diferencia de "Série Branca III", em que a porção do reflexo do céu é simétrico em relação à da porção do rio que reflete o céu. 


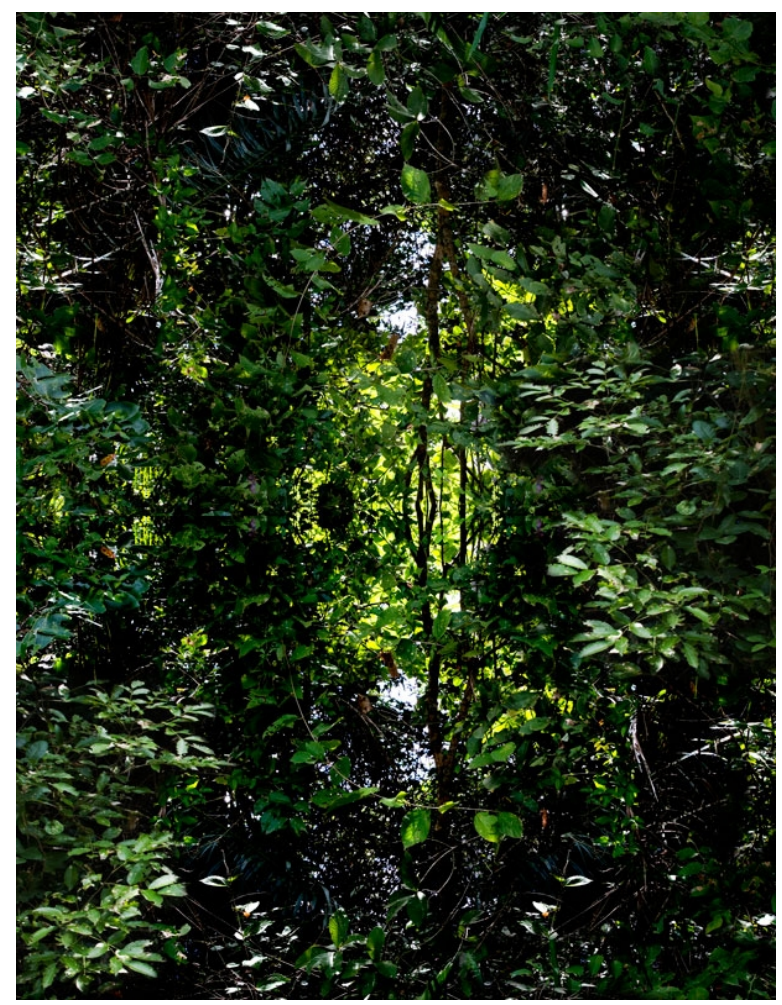

Igarapé, 2007-2008

FONTE: http://www.claudiajaguaribe.com.br

Em "Igarapé", a dificuldade de precisar o limite entre a porção da mata e seu espelhamento na água se dá exatamente porque o espelhamento não se dá de forma simétrica nem uniforme em toda a imagem: nela há porções perfeitamente refletidas ao lado de outras não refletidas. Pode-se inclusive perguntar se algumas porções da imagem não poderiam ter sido acrescentados por montagem, como em “Entre Morros" e "Sobre São Paulo", de 2010 e 2011, respectivamente. Como nesses trabalhos mais recentes, que nublam, pela ação da fotomontagem, a referência entre o que é real e o que é ficcional, a artista acentua a natureza de construção da imagem e reitera o imaginário do ambiente natural como algo intocado, só que a partir do artifício da intervenção digital.

Diante de trabalhos como este, percebe-se como a imagem já não segue a lógica da representação mimética, e sim a de um gesto que torna esses elementos recursos para se produzir uma representação meta-discursiva que não imita o real, mas que o constrói como narrativa, seja de nossas concepções de natureza ou de nossas crenças na verdade das imagens.

\section{Neblina e o contraste homem-natureza}


Por último, em "Neblina” aparece pela primeira e única vez a figura humana em Quando eu vi. A obra é um díptico, formado por duas fotografias impressas em papel metalizado. A primeira com medida de $40 \times 214 \mathrm{~cm}$ e a segunda, $40 \times 60 \mathrm{~cm}$.

O conjunto parece constituir uma espécie de alegoria benjaminiana ${ }^{8}$ da clássica relação entre homem e natureza no contexto das histórias da pintura e da fotografia de paisagem. Na imagem da esquerda temos a mata, e na da direita, que Ihe é contígua mas descontínua, temos uma pessoa que não parece ter nenhum relação com a imagem anterior, a não ser por uma pequena porção de mata do lado direito da imagem e pelo mesmo tom do céu, ao fundo.

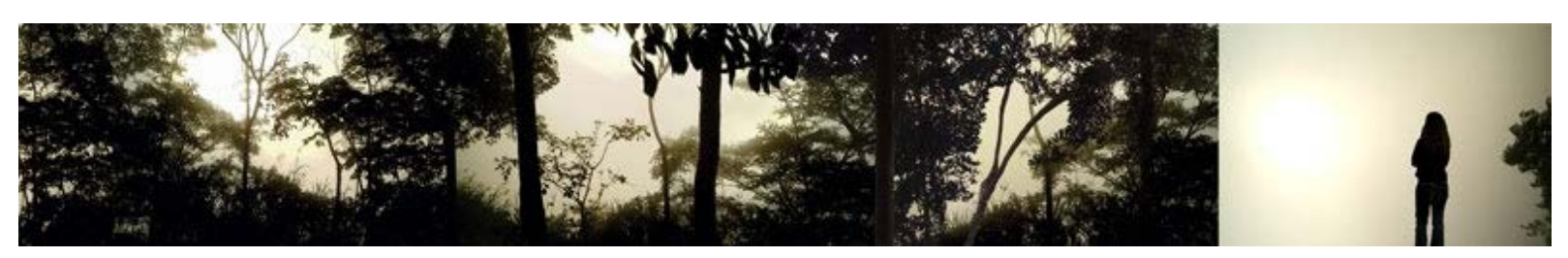

Neblina, 2007-2008

FONTE: http://www.claudiajaguaribe.com.br

Ambas têm em comum, contudo, justamente um tom de cinza levemente sépia, onde as figuras escuras da mata e do ser humano encontram-se em grande contraste claro-escuro com o fundo iluminado. No trabalho, a integração de ambas as partes se dá, mais uma vez, não por uma uniformidade visual, mas pela articulação de uma descontinuidade e de uma fragmentação. No caso, articular de um lado a mata e de outro o humano, fazendo-nos vê-los separados enquanto imagens, mas paradoxalmente integradas numa mesma mirada através do formato de um díptico, o que implica um gesto que vincula e põe em relação imagens que aparentemente não apresentam uma ligação entre si. O que se comunica aqui é, no contexto da história da pintura e da fotografia de paisagem, algumas das questões levantadas pelo gênero: a intervenção do homem na natureza e da invenção da natureza como espaço à parte do "mundo", da experiência do humano e do socius.

Ao montar o díptico, Jaguaribe cria uma forma de representar todo um conjunto de relações que envolvem natureza e humano na história da arte e do Ocidente, dada pela junção do fragmento-mata com o fragmento-humano, que, uma vez juntos, têm o efeito de produzir uma "descontinuidade" visual na imagem embora crie com esta descontinuidade uma continuidade simbólica. Se observarmos atentamente, é possível notar ainda que, apesar de os dois primeiros

\footnotetext{
${ }^{8}$ A alegoria como figura de linguagem usada por Benjamin (2011) implica uma outra forma de relação entre as imagens quando desejamos nos remeter a algo. Com ela, produz-se não um único sentido, mas muitos, nenhum deles literal, de modo a não nos permitir fixar ou determinar um significado a priori para essas imagens (e seus objetos referidos) e para a própria relação entre elas. Diferente da metáfora que ilustra por analogia, a alegoria em Benjamin nos faz pensar a partir das relações entre as imagens que emparelha, sem determinar um significado único para tais relações.
} 
terços da imagem da mata parecerem uma representação verossímil, o terceiro terço não apresenta continuidade com as partes anteriores e parece ter sido acrescentada digitalmente onde precisamente parece existir um tronco que corta longitudinalmente a imagem.

Nessa dinâmica no interior de cada imagem que forma o trabalho e entre cada uma delas na imagem final (o díptico "Neblina"), cada imagem parece ter sido pensada para dar sentido à outra. É tal dinâmica que permite o trabalho não ser apenas uma imagem que se contempla, mas uma forma-pensamento que viabiliza traduzir visualmente os questionamentos da artista: a construção da noção de "paisagem" e de "natureza" na fotografia por meio de usos poéticos da imagem documental.

Como parte das reflexões feitas no âmbito da fotografia contemporânea sobre a natureza da imagem e do arquivo, as paisagens naturais de Jaguaribe exibem os traços de sua fatura, reconstituindo material e simbolicamente os sistemas que modulam nossos modos de ver através da própria mediação que a imagem é. Em Quando eu vi, o documento não renuncia totalmente a seu aspecto de registro e a imagem de natureza não deixa de remeter a lugares reais reconhecidos como "natureza". Porém, na lógica de enunciação não-mimética em que se inscrevem, o documento visual é considerado do ponto de vista do que DidiHuberman (2012) chamou de "aspecto lacunar" da imagem, isto é, como algo necessariamente con-creto, mas parcial e incompleto. Nessa perspectiva, que corresponde ao que Rancière (2010) chamou de "novo estatuto da figura", onde não há nem recusa nem adesão total ou imediata ao índice ou ao documento na imagem, mas figuração do acontecimento, aproximações com o real reveladoras de momentos de "verdade" e de "imaginação" como constitutivo da experiência da imagem.

Isto me parece crucial para os estudos da fotografia na Comunicação, por permitir deslocar a análise da imagem como mensagem visual para a dos processos que constroem seus sentidos e por nos permitir discutir a prática fotográfica como experiência estética. Esse deslocamento importa justamente por vincular necessariamente a fotografia ao ato que a produz e à ecologia da imagem.

Em Quando eu vi, recursos da manipulação digital e da fotomontagem são acionados para paradoxalmente produzir imagens que parecem reais e jogos com a versossimilhança na fotografia. Mas as intervenções na imagem importam menos que um outro tipo mais potente de intervenção: a do gesto conceitual e poético com o qual Jaguaribe discute visual e historicamente a paisagem e a imagem na arte e na fotografia. 


\section{Considerações finais}

Em Quando eu vi, novas paisagens surgem de um trabalho de criação a partir de registros documentais, sem que estes percam totalmente sua capacidade de remeter a um "real". Este gesto, recorrente na fotografia contemporânea, aponta para o que Michel Poivert (2010) chamou de "potencial estético" do documento, ou seja, a capacidade que o documento tem de afetar nossa percepção do real, sem reduzir-se apenas a um discurso ou a uma representação do real, e sem igualmente abrir mão de sua função de organização do visível.

Os trabalhos de Jaguaribe implicam, como vimos, distintas operações que reiteram essa capacidade de afetação da imagem documental, nos níveis do registro, da produção e de sua exibição. O investimento nos médios e grandes formatos, a forma expositiva dos "tableaux", os jogos com o fragmento e com a montagem remetendo às ações de edição - de corte, inclusão e exclusão - são formas de potencializar o gesto de discutir a imagem através da própria imagem.

O resultado dessas operações são imagens onde a paisagem não é apresentada como natureza intocada ou "puro real" representado, mas como construção que the confere um aspecto pitoresco, idealizado, quase fantástico. Num primeiro momento, as imagens parecem se aproximar de uma figuração naturalista e essas paisagens podem ser vistas como testemunho de um lugar existente no mundo. Mas à medida que as observamos, compreendemos que a artista cria uma "natureza" real e ao mesmo tempo inventada.

Não por acaso, em "Branca III e "I garapé", a mata, o céu ou reflexo na água se misturam de forma amalgamada, dificultando o reconhecimento de uma intervenção, que é, na verdade, uma estratégia de problematização da ideia de representação. Nesses casos, apenas por pequenos indícios que a artista decide deixar na imagem, como rastros de sua ação, é que se percebe que o que vemos é fruto de uma intervenção e de uma intenção, embora mal se possa distinguir a fronteira do que é "verdadeiro" e do que é construído. Em outras imagens, como as de "Bibliotecas" e "A mata", fragmentos são claramente assumidos como fragmentos, reiterando a noção de enquadramento e corte fotográficos.

O que resulta desses gestos são imagens que não funcionam como testemunho "do que há para ver", mas daquilo que é possível ver e pensar sobre o que é visto. O documento aqui é, uma vez mais, um resultado possível e visível de um processo de ordenamento da percepção e de um pensamento sensível sobre o real, como o é também a própria paisagem, seja na pintura ou na fotografia.

É assim que as "paisagens naturais" de Jaguaribe dialogam com a história da fotografia de paisagem inscrita na tradição documental e da representação 
figurativa mimética, como vemos desde as vistas de Marc Ferrez, Militão de Azevedo e Malta. Ao mesmo tempo, evidenciam que as ações de escolher, editar, recortar, montar e atribuir significação às imagens para construir paisagens sempre foi algo comum, mesmo nas tradições clássicas da fotografia de paisagem. Como sabemos, o gesto de construir paisagens nunca esteve separado das condições técnicas de sua produção nem de suas funções sociais e tampouco é privilégio da fotografia contemporânea (GONÇALVES, 2014). O que artistas como Claudia Jaguaribe demonstram é que o interesse da fotografia na arte está em tornar evidente as marcas de uma construção onde aparentemente só se acreditava haver transparência e objetividade, questão que muito interessa, por exemplo, ao fotojornalismo, sobretudo no que diz respeito das condições de produção da discursividade da fotografia neste contexto (PICADO, 2014).

Ao dialogar com as histórias da arte e da fotografia, Jaguaribe faz uma releitura crítica da representação mimética da paisagem natural, mas preserva, porém, seu caráter pitoresco como resquício desse modelo para melhor problematizá-lo. Seu trabalho refaz, assim, a história da paisagem natural introduzindo nela novos elementos para uma possível releitura na atualidade. Nessas obras, como em outros de seus trabalhos, apesar do uso da fotomontagem digital, mantêm-se um forte aspecto de verossimilhança com o qual se produz um jogo de indiscernibilidade entre "real" e "ficcional". Com isso, é possível reler e subverter os modelos de representação que buscam "narrar o real" na tradição mimética da fotografia de paisagem, onde a paisagem é concebida normalmente como algo pronto e à espera de ser registrada.

Finalmente, como busquei demonstrar, é por meio de um gesto que devolve à fotografia sua opacidade que a artista busca evidenciar o caráter de construção da imagem, problematizando-o e inscrevendo-o nas discussões sobre a natureza da imagem e de nossos sistemas de representação na fotografia.

\section{Referências}

ALZUGARAY, Paula. [2010]. Aqui é o fim do mundo. Revista Isto é. Artes Visuais, $N^{\circ} \quad$ Edição: 2146.2 Disponível online: http://www. istoe.com.br/reportagens/116420_AQUI +E+O+FIM+DO+MUNDO. Acesso em 22/04/2016.

BENJ AMIN, Walter. Origem do drama barroco alemão. São Paulo: Brasiliense, 2011.

CAUQUELIN, Anne. A invenção da paisagem. São Paulo: Martins Fontes, 2009.

CRARY, J onathan. Suspensões da percepção. São Paulo: CosacNaify, 2013. 
DELOGU, Marco. [2008]. Quando eu vi. Texto de exposição. Disponível online: http://www. claudiajaguaribe.com. br/en/obra/quando-eu-vi-2007-2008/. Acesso em 22/04/2016.

DIDI-HUBERMAN, Georges. I magens apesar de tudo. Lisboa, KKYM, 2012.

$\overline{2} \overline{0} \overline{0} \overline{.}$

Ante el tempo. Buenos Aires: Adriana Hidalgo,

FLORES, Laura Gonzalez. Pintura e fotografia: dois meios diferentes? São Paulo: WMF Martins Fontes, 2011.

FLUSSER, V. Universo das imagens técnicas. São Paulo: Annablume, 2008.

GALASSI, Peter. Before Photography: Painting and the invention of Photography. New York: The Museum of Modern Art, 1981, pp. 11-18.

HARTSHORNE, Richard. The Concept of Geography as a Science of Space, from Kant and Humboldt to Hettner", Annals of the Association of American Geographers, Vol. 48, No. 2 (J un., 1958), pp. 97-108.

MICHAELS, Walter Benn. Photograph and Fossils. In ELKINS, James (Org.) Photography Theory. Routledge: New York and London, 2007.

PICADO, Benjamim. $\mathbf{O}$ olho Suspenso do Novecento: plasticidade e discursividade visual no fotojornalismo moderno. Rio de Janeiro: Azougue. 2014.

POIVERT, Michel. La Photographie Contemporaine. Paris: Flammarion, 2010.

RANCIERE, Jacques. A partilha do sensível: estética e política. Rio de Janeiro: Ed. 34, 2009).

ROUILLÉ, André. A fotografia entre documento e arte contemporânea. São Paulo: Senac, 2009.

SEPPER, Dennis. Understanding imagination: the reason of images. New York: Springer, 2013.

WARBURG, Aby. Histórias de fantasma para gente grande. São Paulo: Companhia das Letras, 2015. 